\title{
Strategies for Peripheral Nerve Repair
}

\section{Matthew Wilcox ${ }^{1,2,3} \cdot$ Holly Gregory ${ }^{1,2} \cdot$ Rebecca Powell ${ }^{1,2} \cdot$ Tom J. Quick $^{3} \cdot$ James B. Phillips ${ }^{1,2}$}

Published online: 21 April 2020

(C) The Author(s) 2020, corrected publication 2020

\begin{abstract}
Purpose of Review This review focuses on biomechanical and cellular considerations required for development of biomaterials and engineered tissues suitable for implantation following PNI, as well as translational requirements relating to outcome measurements for testing success in patients.

Recent Findings Therapies that incorporate multiple aspects of the regenerative environment are likely to be key to improving therapies for nerve regeneration. This represents a complex challenge when considering the diversity of biological, chemical and mechanical factors involved. In addition, clinical outcome measures following peripheral nerve repair which are sensitive and responsive to changes in the tissue microenvironment following neural injury and regeneration are required.

Summary Effective new therapies for the treatment of PNI are likely to include engineered tissues and biomaterials able to evoke a tissue microenvironment that incorporates both biochemical and mechanical features supportive to regeneration. Translational development of these technologies towards clinical use in humans drives a concomitant need for improved clinical measures to quantify nerve regeneration.
\end{abstract}

Keywords Nerve regeneration · Nerve biomechanics · Repair Schwann cells · Quantitative MRI · Quantitative neurophysiology

\section{Introduction}

Peripheral nerve injuries (PNI) are common following blunt or penetrating trauma, accounting for around $2 \%$ of all trauma cases [1, 2]. PNI are debilitating, leading to loss of sensation and movement and, in many cases, chronic pain for those affected, resulting in significant global socio-economic ramifications. The leading cause of PNI is vehicular collisions, and the people affected are predominantly young males [2].

Although the peripheral nervous system (PNS) has the capacity to regenerate to some extent, muscle function is often considered by patients to be incomplete [3]. Optimal

This article is part of the Topical Collection on Biomimetic Approaches ins Regenerative Medicine

James B. Phillips

jb.phillips@ucl.ac.uk

1 Department of Pharmacology, UCL School of Pharmacy, University College London, 29-39 Brunswick Square, London WC1N 1AX, UK

2 UCL Centre for Nerve Engineering, University College London, London, UK

3 Peripheral Nerve Injury Research Unit, Royal National Orthopaedic Hospital, Stanmore, UK functional reinnervation is dependent upon a sufficient number and quality of regenerating axons reaching their target within 1 year following injury [4-6]. Beyond this time period, functional outcomes are often disappointing [6]. This has been attributed to phenotypic changes in the microenvironment of the denervated nerve and muscle such that an incremental delay in reinnervation decreases the likelihood of functional recovery [4-6]. This is pertinent in proximal nerve injuries due to the slow rate of human nerve regeneration (approximately $1 \mathrm{~mm} /$ day) [7].

The most severe nerve injuries often benefit from operative intervention. Over recent decades, advancements in reconstructive surgery have improved functional outcomes. The nerve autograft, nerve transfer and free functioning muscle transfer (FFMT) (Fig. 1) are commonly deployed surgical strategies to restore function following severe PNI $[4,6,8,9]$. These interventions aim to provide a tissue microenviroment that supports neural regeneration and/or minimise regeneration distances. Nerve autografting is associated with a number of limitations. Surgical transection of donor tissues leads to loss of donor nerve function, tissue remodelling and scar tissue formation. This permanently changes the biomechanical properties of tissues which can affect normal function of tendons, muscles and/or nerves [10]. Second, the availability of suitable donor sites where tissue 
a)

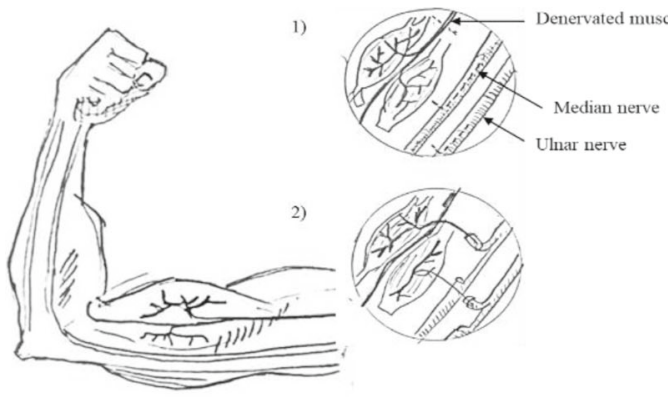

b)

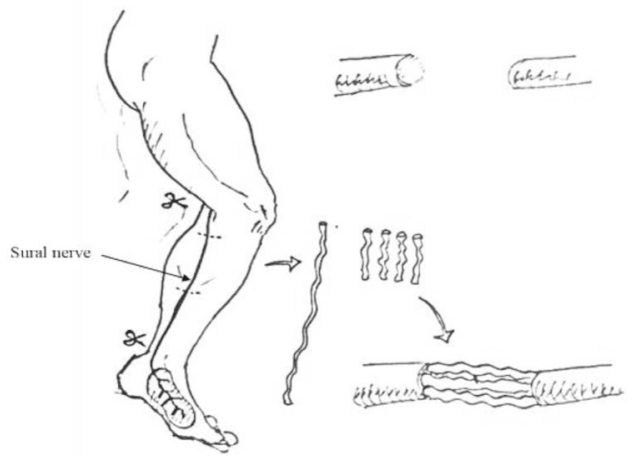

Fig. 1 Reconstructive nerve procedures. a Nerve transfer is commonly deployed in severe proximal nerve injuries to restore elbow flexion (Oberlin's nerve transfer). Synergistic donor motor nerves (fascicles ulnar and median nerves to wrist flexors) in close proximity to the injured nerve (musculocutaneous nerve) are dissected, divided and redirected to grow into the damaged nerve. b The nerve autograft is

for grafting can be liberated within patients is limited. Together, this has stimulated research into drug treatments that accelerate nerve regeneration and tissue engineered therapeutics which maintain the distal environment to support muscle reinnervation $[11,12]$.

To date, research to improve outcomes following peripheral nerve repair has largely focused upon either the biochemical or mechanical environment in isolation [13-16]. Therapies that incorporate multiple aspects of the regenerative environment are likely to be key to improving therapies for nerve regeneration (Fig. 2). However, this represents a complex challenge when considering the diversity of biological, chemical and mechanical factors involved. Mathematical and/or in silico modelling can be utilised to resolve this complexity in order to inform clinicians and researchers about how to optimise treatments. In addition, clinical outcome measures following peripheral nerve repair which are sensitive and responsive to changes in the tissue microenvironment following neural injury and regeneration are awaited. Addressing these challenges will important in developing effective therapies for the treatment of PNI. This review will consider the key aspects of the nerve tissue microenvironment that underpin development of new strategies for peripheral nerve repair. In particular it will cover biomechanical and cellular considerations required for development of

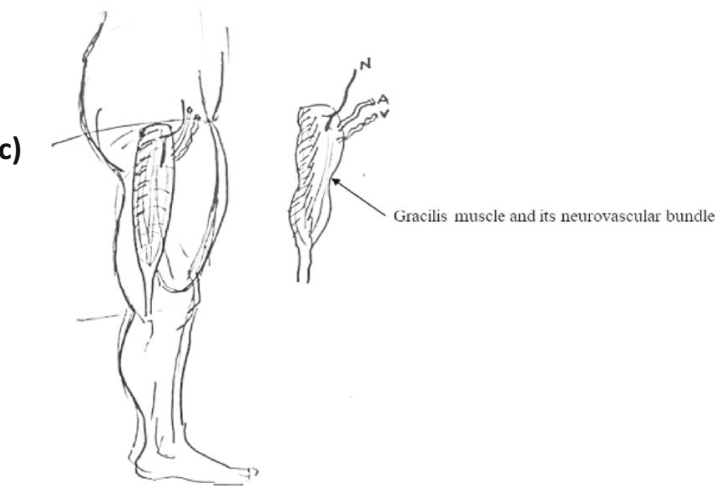

often selected to repair excessive acute gaps. A sensory (often sural) nerve is harvested and used to bridge the nerve gap. $\mathbf{c}$ Free functioning muscle transfer is elected in chronic nerve injuries. A donor muscle (such as the gracilis) and its neurovascular bundle are removed and grafted into the site of injury to restore function (such as elbow flexion). $N$, nerve; $A$, artery; $V$, vein

biomaterials and engineered tissues suitable for implantation following PNI, as well as translational requirements relating to outcome measures for testing success in patients (Fig. 2).

\section{Mimicking the Biomechanical Properties of the PNS}

The biomechanical properties of peripheral nerves are vital to the development of better surgical options and biomaterials for nerve repair constructs. Peripheral nerve structure is arranged systematically, in which axons supported by Schwann cells and endoneurial tissue are bound together in fascicles by perineurium, a layer composed of concentric flat perineurial cells containing tight junctions [17]. A number of fascicles, in conjunction with blood vessels, are grouped together and encompassed by epineurium to form a nerve. Collagen fibrils are arranged longitudinally within the endoneurium and throughout the perineurium and epineurium, where they form a meshwork of larger fibre structures that provides strength and flexibility [18]. This structure allows the nerve to function effectively under the stresses imparted by normal movement, bestowing tensile strength and elasticity [19-22]. During movement, peripheral nerves glide relative to the surrounding muscle and bone, and nerve fascicles slide independently of one another [23, 24]. When the whole nerve is under tensile load, it both elongates axially 


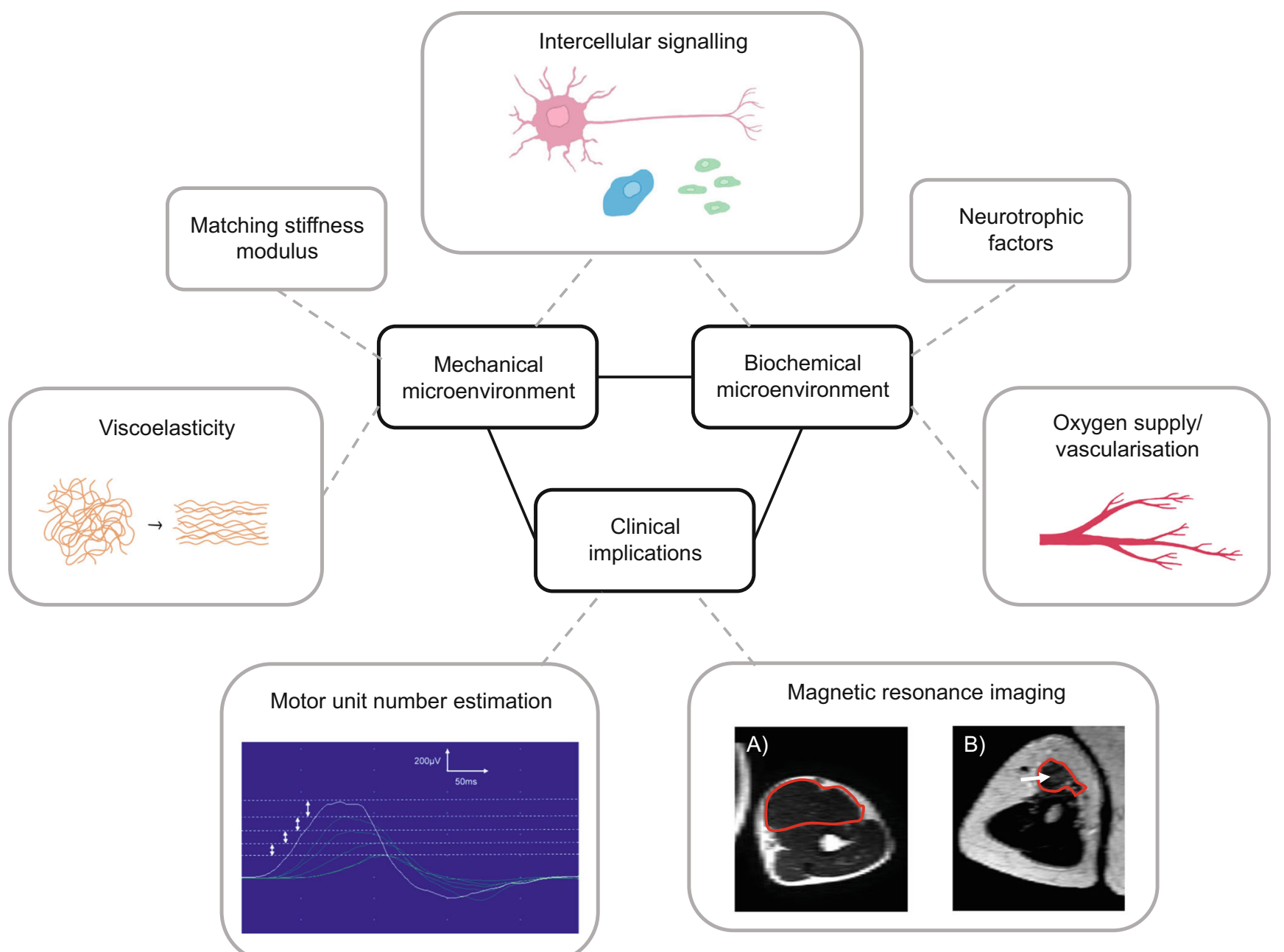

Fig. 2 Strategies to improve peripheral nerve repair. Effective new therapies for peripheral nerve repair are likely to include engineered tissues and biomaterials that incorporate biological and mechanical features to support regeneration. Translational development of these technologies towards clinical use in humans requires improved clinical outcome measures of nerve regeneration. Motor unit number estimation: serial single motor unit potentials recorded from rat tibialis anterior using

and compresses across the circumference non-linearly - the tissue elongates faster and the circumference decreases more quickly at lower tensile loading [25].

Human nerve tissue is relatively soft - the modulus of ulnar nerve has been measured as $12 \mathrm{kPa}$ in vitro and $54 \mathrm{kPa}$ in vivo [26]. Like the majority of biological tissue nerve tissue displays viscoelastic behaviour, which means they can be considered to have both elastic components and viscous components [27]. Elasticity is evident in human nerve, which can be elongated up to $6 \%$ without damage [28], and in fact nerves are under constant physiological strain. In situ measurements of rabbit tibial nerve demonstrate minimal stress at a strain of $11 \%$ [21], and rat sciatic nerve retracts around $11 \%$ when severed [29]. However, the window of tolerated force is narrow. Kwan an incremental stimulation technique. Magnetic resonance imaging: T2weighted MRI scans of uninjured and nerve injured biceps muscles from patient who sustained C5/6 Avulsion. a Uninjured biceps muscle (uninjured contralateral arm) outlined in red. b Subacutely denervated biceps muscle (3 months following injury) demonstrating increased signal (arrow) and atrophy of the biceps muscle (outlined in red) compared to a

and co-workers found that increasing the percentage strain on rabbit tibial nerve in situ from 6 to $12 \%$ increased the likelihood of non-recoverable conduction block, and increasing applied stress up to $1.75 \mathrm{MPa}$ reduced the compound nerve action potential to less than $20 \%$ of the baseline value after a 1-hour recovery period [21].

Nerve tissue also demonstrates a property common to viscoelastic materials in that the speed of elongation determines the ability of the tissue to withstand strain. Ikeda et al. stretched the rabbit sciatic nerve by $30 \mathrm{~mm}$ through femur elongation at $0.8 \mathrm{~mm} / \mathrm{day}$, which was found to cause little nerve damage, whereas $2.0 \mathrm{~mm} /$ day tended to cause recoverable damage, and $4.0 \mathrm{~mm} /$ day tended to produce irreversible damage [30]. Other viscoelastic behaviours exhibited by peripheral nerves include stress relaxation, in which the stress 
needed to maintain a certain strain reduces with time; and creep, where the strain produced by a set stress will increase with time. These behaviours have been demonstrated in cadaveric human sciatic nerve [31], and are valuable in allowing nerve tissue to adapt to stress from body movement.

It is important to note that injury may alter the mechanical behaviour of nerves. Mouse sciatic nerve after crush injury demonstrated increased nerve strength and stiffness and decreased elasticity compared to uninjured nerves, effects which increased up to 12 days post-crush for strength and stiffness and 24 days post-injury for elasticity [32]. In cadaveric human digital nerve, crush injury had no effect on the ultimate tensile strength, stiffness, maximum stress or strain of the tissue [33]. However, this result is unsurprising given that post-injury increase in stiffness and loss of elasticity may be due to fibrosis in the neural tissue [24, 34], a physiological reaction which would not be present in cadaveric samples.

An understanding of native nerve mechanics is important if tissue engineers are going to replicate it effectively in biomaterial constructs, used as an alternative to the autograft to bridge long gaps in nerve tissue. As is evident in this review and others [24], much of the recent mechanical data available are from animal models and relatively few studies use human tissue. The mechanical properties of native nerve must be more thoroughly investigated and reproduced as closely as possible in the design of biomimetic constructs for nerve repair.

To imitate the complex mechanical environment of peripheral nerve, the material should be relatively soft to match the modulus of nerve tissue and elastic to accommodate the considerable strain that peripheral nerve endures without damage. The construct material must also maintain enough stiffness to prevent the surrounding tissue from swelling into the gap between nerve ends and blocking the path of regenerating axons. This balance is difficult to strike - the results from clinical trials of three FDA-approved bioabsorbable peripheral nerve conduits have been published in peer-reviewed journals [35], and even these constructs may not possess appropriate mechanical properties. An independent study comparing them with an autograft in a $10-\mathrm{mm}$ rat sciatic nerve gap found the polyglycolic acid conduit to have collapsed completely after 12 weeks in all animals [36]. The authors note that this could be attributed to a size mismatch in using conduits intended for human nerves in a rat model, however also point out that these conduits were used successfully in human facial nerve [37] which would also have a relatively small diameter compared to the conduit. Constructs which are too stiff can be equally detrimental to recovery. Matching the mechanical modulus of a rat peripheral nerve implant environment by coating poly(dimethylsiloxane) (PDMS) implants in soft $(<10 \mathrm{kPa})$ polyacrylamide or PDMS gel was found to suppress inflammation and reduce foreign body response compared to implants with stiffer moduli [38]. In general the mechanical microenvironment is hugely impactful on the cellular environment - the lineage and phenotype of mesenchymal stem cells (MSCs) has been shown to be specified by matrix elasticity, and softer matrices found to encourage a neurogenic phenotype [39].

Belanger and co-workers recently designed a trilayered electrospun silk fibre material for nerve repair which utilised aligned outer layers for axonal guidance and a randomly orientated inner layer [15]. The trilayer material had comparable stiffness to a purely aligned material (and to rat sciatic nerve) and demonstrated improved ductility, which the authors suggest and is explained by the rearrangement and alignment of the randomly orientated fibres in the direction of tensile stress. The authors also suggest that the trilayer material demonstrated better surgical handling properties due to increased tear strength [15]. Electrospun fibre conduits with and without alignment have also been developed using polycaprolactone and chitosan [40]. The researchers found the fully aligned conduit had improved compression properties but reduced tensile strength due to sudden breakage of the orientated fibres. In a $10 \mathrm{~mm}$ rat sciatic nerve model, the aligned conduit displayed a number of improved in vivo regenerative indicators compared with the randomly aligned material [40].

A number of technologies based on synthetic materials have been developed to more closely imitate the mechanical behaviour of biological tissues. Implantable electric devices which record and modulate signals in the PNS, known as peripheral nerve interfaces, are currently designed using flexible and stretchable silicone-based elastomers such as PDMS, which provide high extensibility and relatively low Young's modulus values [41]. A system which can reproduce strain stiffening behaviour has been developed based on brushand comb-like polymer networks and allows precise replication of specific tissue characteristics based on network strand length, polymer grafting density and side chain length [42]. Similarly, a combination of polyethylene glycol and branched polyethylenimine has been used to create a strain stiffening and self-healing flexible hydrogel which mimics the mechanical response of a biological system to stress [43]. Although these systems and others may have application in materials for nerve constructs, mechanical performance to match that of the nerve microenvironment is in general rarely considered during material development in constructs for nerve repair. However, current work in mathematical modelling is aiding our understanding of the complex mechanical environment of neural tissue and is becoming a vital tool in development of biomaterial constructs. For example, Giannessi et al. used a polynomial strain energy function to model the mechanical response to stretch of nerve from different species and built in silico models of porcine nerve and Aplysia cerebro-abdominal tissue [44]. The authors note that although the model was focused on nerve hyperelasticity, elements such as viscosity could be included to allow computational modelling of nerves during regeneration through scaffolds. 


\section{Creating a Tissue Microenvironment that Supports Regeneration}

The cellular components of a peripheral nerve have distinct and essential roles to play during peripheral nerve injury and repair, the key component being Schwann cells. Only hours after an axonal transection injury, Schwann cells transform to a 'repair' phenotype. These do not produce myelin and undergo autophagy to break down existing myelin. Expression of growth factors, such as glial cell line-derived neurotrophic factor (GDNF) and nerve growth factor (NGF), is upregulated, as well as cytokines that can recruit macrophages. Repair Schwann cells adopt a longer bipolar morphology as they proliferate [45••], and form tracks called bands of Büngner which guide new axons and prevent misdirection of reinnervation [46]. Wallerian degeneration, where axons and myelin degrade within the distal nerve, starts after an injury. Macrophages infiltrate at this stage to phagocytose cellular and tissue debris, establishing a pro-regenerative environment for new axon growth. In larger nerve gaps, an autograft is the current clinical standard of care for reconstruction [47]. Inserting a length of healthy nerve as an autograft initiates the repair process in the grafted nerve bridge, transferring a column of repair Schwann cells into the injury site that can guide axon growth from the proximal stump. Mimicking this biological microenvironment provides the motivation for peripheral nerve repair through tissue engineering.

There are two main roles of repair Schwann cells in the peripheral nerve injury microenvironment - nerve regeneration support through the release of neurotrophic factors and physical guidance of the regenerating axon. Cell therapies so far have focused a great deal on neurotrophic factor release. Mesenchymal stem cells (MSCs) have been widely used in research and are an attractive option due to availability, ability to differentiate into neural cell types and the expression of neurogenic and immunoprotective factors. However, MSCs are also ill-defined and are often a mixed population from a variety of sources - from the most common bone marrow [48] and adipose-derived $[49,50]$ to Wharton's jelly [51] and tonsil-derived [52]. High variability in numbers, function and sources makes large-scale expansion more complex. More defined cell sources are embryonic stem cells (ESCs) and induced pluripotent stem cells (iPSCs). As iPSCs are created from adult cells $[53,54]$, they are advantageous over embryonic stem cells (ESCs) due to reduced ethical complications which would present difficulties when implementing an ESC-based therapy worldwide [55]. iPSC therapy has been pushed forward to clinical trials in Japan [56॰], and the US [57], and so far this type of cell therapy has been reported as safe [58].

iPSCs can be differentiated into Schwann cells via a precursor stage $[59,60]$, with Schwann cells being seen as the ideal cell type for therapy due to the key role they have in the repair process $[45 \bullet, 46,61]$. The repair Schwann cells in the nerve autograft show greater similarity to ES cells than neural crest cells [62]. For this reason, it is possible that cells at earlier stages of differentiation will support regeneration to a greater degree than terminally differentiated Schwann cells [60]. iPSC-derived Schwann cell precursors and Schwann cells have shown significant functional improvement compared to controls without cell therapy [59], with key outcomes being neurotrophic factor release and increased myelin formation.

Extracellular vesicles, exosomes and secretomes have benefits over cell therapies because of the challenges around patient matching for allogeneic cell therapies, as well as manufacturing challenges regarding cell supply and quantity. In one study, a $10 \mathrm{~mm}$ gap in rats was repaired with a chitin conduit alongside injection of exosomes from gingiva-derived mesenchymal stem cells. The group treated with exosomes showed equivalent recovery in nerve fibre myelination and muscle weight to the autograft group after 12 weeks, which was significant compared to the empty conduit [63]. Exosomes isolated from differentiated ADSCs have been shown in vitro to reduce apoptosis of Schwann cells [64] and those from undifferentiated ADSCs promote neurite outgrowth of NG108-15 cells [65]. This suggests that a key role of transplanted stem cells in peripheral nerve repair is the release of neurotrophic factors; although without living cells present to release neurotrophic factors continuously, secretome-based therapies might be limited to short-term effects.

Neurotrophic factors, although essential to the regeneration of an axon, must be delivered in a controlled manner. For example, excess levels of GDNF can be detrimental to nerve repair, causing nerve sprouting and axon entrapment [66]. Neurotrophic factors have potential to be delivered as a drug, although gene edited cell therapies that allow controlled release of neurotrophic factors are an attractive option. By combining expression of specific neurotrophic factors such as GDNF [66] or the upstream transcription factor c-Jun [67•] with a Tet-On/Tet-Off system, the delivery can be carefully controlled to avoid overexpression and off-target reinnervation [66].

Neurotrophic factor release is not the only role of repair Schwann cells. Repair Schwann cells also interact with other cells at the injury site to ensure successful reinnervation. Dun et al. have found complementary attraction and repulsion signalling interactions between repair Schwann cells, macrophages and fibroblasts via the Slit-Robo pathway [68, 69], which are essential for formation of the nerve bridge and directing regenerating axons. Macrophages surrounding the nerve bridge express Slit3, which binds to the Robo1 expressed by repair Schwann cells and acts as a repellent force ensuring repair Schwann cell migration remains directed along the nerve bridge. Repair Schwann cells also interact with blood vessels, which form early across the nerve bridge 
and help guide Schwann cells [70]. Blood vessel formation is also regulated by macrophages releasing VEGF [70], as well as the interaction between Robo1 on blood vessels and Slit3 on macrophages [68]. There is a network of cell-cell interactions in a nerve bridge that together result in successful regeneration. Mimicking these intercellular interactions will be an important part of ensuring new engineered tissue therapies succeed.

Nerve graft hypoxia is not well characterized. Injury results in the damage of blood vessels, leading to hypoxia around the peripheral nerve injury bridge. Short-term hypoxia may induce some advantageous changes - it has been found to enhance c-Myc transcription in cell lines [71], and to promote vascularisation [72-74], but long-term hypoxia will lead to cell death [75]. VEGF, expressed by macrophages in the nerve bridge [70], is essential to promote blood vessel growth [76]. Indeed, just delivering VEGF can improve functional outcomes following nerve injury in mice [77], and having therapeutic cells that promote angiogenesis in a construct are likely to improve survival of the implanted cells and be beneficial for nerve repair [73].

The biological microenvironment in a peripheral nerve injury site involves a complex network of cells that support axon regeneration through neurotrophic factor release and physical guidance cues. The interaction between cells in the nerve repair site and those in the surrounding tissue are essential to successful regeneration, ensuring both axon regeneration and vascularisation are supported and guided. Mimicking this microenvironment will involve a combination of existing technologies, and mathematical modelling can untangle the complexity to ensure the most important factors that can be prioritised [78].

\section{Challenge of Clinical Translation}

A number of therapeutics for the treatment of PNI have been developed in animal models, including engineered tissues that mimic the regenerative microenvironment found in the nerve autograft and distal nerve segment [73, 79-82]. However, there are many challenges associated with the clinical translation of these and other therapies with the potential to improve nerve repair outcomes in patients. First, little is known about the in vivo biology of human nerve regeneration. Second, assessments that are sensitive and responsive to sub-clinical changes in the tissue microenvironment are still under development.

\section{Human Nerve Regeneration}

Whilst a great deal is known about the cellular and molecular signals that underpin nerve regeneration in rodents [45••, 83], it is unknown whether these are mimicked in humans. There are a number of challenges associated with studying human nerve regeneration which are not encountered in animal models. It is challenging to liberate human nerve samples for study in the laboratory without creating significant patient morbidity. Even when there are opportunities to retrieve finite amounts of excess human nerve from some reconstructive nerve procedures (such as the nerve autograft and nerve transfer) for experimental use, there are a number of perioperative variables that must be considered. A recent study demonstrated the deleterious effect of surgical antiseptics and time delays (as short as $3 \mathrm{~min}$ ) on the quality and quantity of RNA isolated from human nerve samples [84]. Additional advances in the techniques used to study the nerve tissue microenvironment in humans are required in order to understand the differences and similarities between rodent models and their human patient counterparts. Since human nerve tissue is likely to remain a rare resource for experimental study, approaches that maximise the yield of RNA and the detection of other tissue biomarkers will be valuable, as will new clinical assessment measures and non-invasive imaging.

\section{Clinical Assessments}

Clinical assessments of nerve injury are ultimately an assessment of function, i.e. the extent to which damaged neurons have successfully reinnervated their target organs to restore sensation and/or control of muscle contraction. The recovery of motor function is universally assessed using manual muscle testing and in particular the Medical Research Council (MRC) grading system (Table 1) of peak volitional force. This assessment of muscular function has been shown to be limited for a number of reasons with over $96 \%$ of recordings being classified as MRC Grade 4 [86]. This has stimulated a shift towards the use of continuous measurements of peak volitional force using handheld dynamometry [87]. However, patient reported experiences of muscle reinnervation have demonstrated that an earlier onset of fatigue is a central theme of muscle reinnervation [88-90]. In the context of motor function, muscle fatigue can be defined as the inability to sustain force over time [91]. Recent studies have shown that surface electromyography (EMG) measurements during sustained and repeated isometric contraction of reinnervated muscle may be used to monitor muscle fatigue $[88,90]$. Adoption of these metrics

Table 1 The MRC grading system of muscle power [85]

\begin{tabular}{ll}
\hline MRC Grade & Clinical presentation \\
\hline 0 & No movement \\
1 & Flicker of movement \\
2 & Active movement when gravity removed \\
3 & Active movement against gravity only \\
4 & Active movement against resistance \\
5 & Normal muscle power \\
\hline
\end{tabular}


into clinical assessments of muscular function will be the key to driving advancements in motor recovery therapy. Diagnostic tests such as neurophysiology and imaging may also present useful tools to quantify changes in the tissue microenvironment associated with nerve regeneration.

\section{Neurophysiology}

Nerve conduction studies (NCS) and EMG are the first-line tests used by clinicians to determine the location and extent of nerve damage [92]. NCS measure the speed and amplitude of currents passed along nerves, whilst EMG provides an impression of nerve function and its interaction with the muscle [93]. However, many of these neurophysiological changes provide limited information about the functional microenvironment at the interface between regenerated nerve and muscle, i.e. the number of functional motor units. Motor unit number estimation (MUNE) is a neurophysiological test that estimates the number of motor units (MUs) innervating a muscle. MUNE is based on the phenomenon that it is possible to recruit individual MUs by incrementally increasing stimulation to the nerve and its muscle [94] (Fig. 2). MUNE has been utilised as a tool to characterise the dynamics of a number of pathologies associated with muscle denervation such as amyotrophic lateral sclerosis (ALS) and spinal muscle atrophy (SMA), and has been used as a primary outcome measure in clinical trials [95-97]. Application of MUNE in muscle reinnervation is not well documented, but a number of methods to determine MUNE have been reported [95, 98, 99]. If changes in the tissue microenvironment during nerve regeneration can be correlated with MUNE, this might provide a useful minimally invasive way to quantify both animal and human nerve regeneration $[100 \bullet \bullet]$.

\section{Imaging}

Imaging is widely employed in the clinical work-up of patients with central nervous system (CNS) pathologies but is not in widespread use for peripheral nerve disorders. This is despite a number of studies demonstrating changes evident on MRI scans that are associated with the injured nerve and skeletal muscle [101]. It is hoped that these markers may provide sensitive and responsive measures of changes in the tissue microenvironment associated with injury and regeneration.

\section{MRI of Peripheral Nerve Lesions}

Uninjured nerves demonstrate a signal that is isointense or moderately hyperintense compared to the surrounding muscle on a T2-weighted (T2-w) image. By extension, it is often difficult to distinguish between an uninjured nerve and its surrounding muscle. However, when an injury has caused axonal loss within the nerve trunk, it is possible to distinguish between the nerve and surrounding muscle. The injured nerve will demonstrate an increase in $\mathrm{T} 2$ relaxation time and will appear "bright" on a T2-w scan as soon as $24 \mathrm{~h}$ following injury [102, 103]. The signal change regresses back towards normal levels following successful nerve regeneration and is well correlated with the return of motor function [104, 105]. In addition, these changes on MRI precede EMG markers associated with recovering voluntary activity $[105,106]$. It remains largely unknown what these changes in T2 relaxation time correlate to within the tissue microenvironment although an increase in extracellular volume is thought to be responsible [104, 105, 107].

Diffusion tensor imaging and tractography provide a graphical representation of the microanatomy of nerves [108]. However, the sensitivity of these techniques must be improved in order to image changes in the nerves associated with injury or compression following trauma [108]. It must also be elucidated what relationship these images have with function.

\section{MRI of Denervated Muscle}

Normal muscle appears as an intermediate signal on T1weighted (T1-w) and T2-w images. Denervated muscle demonstrates hyperintense signals on fluid sensitive MRI sequences (such as short tau inversion recovery (STIR) and turbo inversion recovery magnitude (TIRM)) [103, 109-111]. Upon successful nerve regeneration, the hyperintense signal regresses back towards normal levels [101, 106, 112], and these changes precede EMG markers of recovery [101, 106, 112]. The cellular and molecular mechanisms in the tissue microenvironment responsible for these changes remain poorly understood, and quantification in a standardised model of muscle reinnervation is required.

A number of changes in the tissue microenvironment take place following muscle denervation. The loss of neural trophic support leads to muscle atrophy and fat infiltration (Fig. 2). In prolonged denervation, this ultimately leads to a loss of muscle mass. The recovery of rat gastrocnemius muscles was found to range from 19 to $100 \%$ of the uninjured contralateral side following immediate nerve repair [113-115]. However, the outcome is much poorer when nerve repair is delayed beyond 3 months following injury, with muscle wet weight recovering to only 10-20\% of the uninjured contralateral side [113-115]. Changes in muscle wet weight and MRI signal could theoretically be used to monitor and predict functional recovery following peripheral nerve repair. However, measurement of muscle wet weight in humans is not possible, although recent pilot studies have explored muscle volumetric changes associated with facial muscle reinnervation [116, 117].

It would be useful to quantify changes in MRI signal and muscle volume in a model of muscle reinnervation. 
Understanding the relationship between these MRI changes and objective and subjective measurements of muscular function will help with the validation and widespread adoption of MRI as a clinical and research tool in PNI.

\section{Ultrasound}

Ultrasound (US) can be used in the acute phase of nerve injuries where it has a role in identifying the level of injury and entrapment pathologies [118]. High-resolution US has been shown to be a highly sensitive method for differentiating between axonotmesis and neurotmesis injuries preoperatively $[110,112]$. However, this technique is highly operator-dependent, and imaging of deeper nerves is often challenging.

\section{Conclusions}

Effective new therapies for the treatment of PNI are likely to include engineered tissues and biomaterials able to evoke a tissue microenvironment that incorporates both biological and mechanical features supportive to regeneration (Fig. 2). Translational development of these technologies towards clinical use in humans requires improved understanding of the human nerve and muscle microenvironment and drives a concomitant need for improved clinical measures to quantify nerve regeneration. This will require the engagement and collaboration of multidisciplinary teams that incorporate scientists, engineers, clinicians and mathematical modellers in order to drive innovation and improve therapeutic options in this field.

Acknowledgements This work was funded by the Medical Research Council (MR/N013867/1), Engineering and Physical Sciences Research Council (EP/L01646X/1), a UCL Graduate Research Scholarship and the England Golf Trust.

\section{Compliance with Ethical Standards}

Conflict of Interests The authors declare that they have no conflict of interest.

Ethical Approval This study does not contain any studies with human participants or animals performed by any of the authors.

Open Access This article is licensed under a Creative Commons Attribution 4.0 International License, which permits use, sharing, adaptation, distribution and reproduction in any medium or format, as long as you give appropriate credit to the original author(s) and the source, provide a link to the Creative Commons licence, and indicate if changes were made. The images or other third party material in this article are included in the article's Creative Commons licence, unless indicated otherwise in a credit line to the material. If material is not included in the article's Creative Commons licence and your intended use is not permitted by statutory regulation or exceeds the permitted use, you will need to obtain permission directly from the copyright holder. To view a copy of this licence, visit http://creativecommons.org/licenses/by/4.0/.

\section{References}

Papers of particular interest, published recently, have been highlighted as:

- Of importance

•- Of major importance

1. Saadat S, Eslami V, Rahimi-Movaghar V. The incidence of peripheral nerve injury in trauma patients in Iran. Ulus Travma Acil Cerrahi Derg. 2011;17:539-44.

2. Huckhagel T, Nüchtern J, Regelsberger J, Lefering R, TraumaRegister DGU. Nerve injury in severe trauma with upper extremity involvement: evaluation of 49,382 patients from the TraumaRegister DGU® between 2002 and 2015. Scand J Trauma Resusc Emerg Med. 2018;26:76.

3. Scheib J, Hoke A. Advances in peripheral nerve regeneration. Nat Rev Neurol. 2013;9:668-76.

4. Isaacs J, Cochran AR. Nerve transfers for peripheral nerve injury in the upper limb. Bone Joint J. 2019;101-B:124-31.

5. Griffin MF, Malahias M, Hindocha S. Peripheral nerve injury: principles for repair and regeneration. Open Orthop J. 2014;8: 199-203.

6. Tung TH, Mackinnon SE. Nerve transfers: indications, techniques, and outcomes. J Hand Surg Am. 2010;35:332-41.

7. Seddon HJ, Medawar PB, Smith H. Rate of regeneration of peripheral nerves in man. J Physiol. 1943;102:191-215.

8. Dahlin LB. Techniques of peripheral nerve repair. Scand J Surg. 2008;97:310-6.

9. Seal A, Stevanovic M. Free functional muscle transfer for the upper extremity. Clin Plast Surg. 2011;38:561-75.

10. Guelinckx PJ, Faulkner JA, Essig DA. Neurovascularanastomosed muscle grafts in rabbits: functional deficits result from tendon repair. Muscle Nerve. 1988;11:745-51.

11. Bota O, Fodor L. The influence of drugs on peripheral nerve regeneration. Drug Metab Rev. 2019;51:266-92.

12. Lopez J, Quan A, Budihardjo J, et al. Growth hormone improves nerve regeneration, muscle re-innervation, and functional outcomes after chronic denervation injury. Sci Rep. 2019;9:3117.

13. $\mathrm{Gu} \mathrm{X}$, Ding F, Williams DF. Neural tissue engineering options for peripheral nerve regeneration. Biomaterials. 2014;35:6143-56.

14. He L, Tian L, Sun Y, Zhang Y, Xue W, So KF, et al. Nanoengineered environment for nerve regeneration: scaffolds, functional molecules and stem cells. Curr Stem Cell Res Ther. 2016;11:605-17.

15. Belanger K, Schlatter G, Hébraud A, Marin F, Testelin S, Dakpé S, et al. A multi-layered nerve guidance conduit design adapted to facilitate surgical implantation. Heal Sci Reports. 2018;1:e86.

16. Zargar Kharazi A, Dini G, Naser R. Fabrication and evaluation of a nerve guidance conduit capable of $\mathrm{Ca}(2+)$ ion release to accelerate axon extension in peripheral nerve regeneration. J Biomed Mater Res A. 2018;106:2181-9.

17. Peltonen S, Alanne M, Peltonen J. Barriers of the peripheral nerve. Tissue Barriers. 2013;1:1-6.

18. Ushiki $\mathrm{T}$, Ide $\mathrm{C}$. Three-dimensional organization of the collagen fibrils in the rat sciatic nerve as revealed by transmission- and scanning electron microscopy. Cell Tissue Res. 1990;260:175-84.

19. Sunderland S, Bradley KC. Stress-strain phenomena in human peripheral nerve trunks. Brain. 1961;84:102-19.

20. Rydevik BL, Kwan MK, Myers RR, Brown RA, Triggs KJ, Woo SL, et al. An in vitro mechanical and histological study of acute stretching on rabbit tibial nerve. J Orthop Res. 1990;8:694-701. 
21. Kwan MK, Wall EJ, Massie J, Garfin SR. Strain, stress and stretch of peripheral nerve rabbit experiments in vitro and in vivo. Acta Orthop. 1992;63:267-72.

22. Millesi H, Zoch G, Reihsner R. Mechanical properties of peripheral nerves. Clin Orthop Relat Res. 1995:76-83.

23. Tillett RL, Afoke A, Phillips JB, Brown RA. Investigating the mechanical behaviour at a core-sheath interface in peripheral nerves. J Peripher Nerv Syst. 2004;9:255-62.

24. Topp KS, Boyd BS. Structure and biomechanics of peripheral nerves: nerve responses to physical stresses and implications for physical therapist practice. Phys Ther. 2006;86:92-109.

25. Bianchi F, Hofmann F, Smith AJ, Ye H, Thompson MS. Probing multi-scale mechanics of peripheral nerve collagen and myelin by X-ray diffraction. J Mech Behav Biomed Mater. 2018;87:205-12.

26. Ma Z, Hu S, Tan JS, Myer C, Njus NM, Xia Z. In vitro and in vivo mechanical properties of human ulnar and median nerves. $\mathrm{J}$ Biomed Mater Res - Part A. 2013;101(A):2718-25.

27. Sasaki N. Viscoelastic properties of biological materials. Viscoelasticity - From Theory to Biol Appl; 2012. https://doi. org/10.5772/57353.

28. Liu CT, Benda CE, Lewey FH. Tensile strength of human nerves. Arch Neurol Psychiatr. 1948;59:322-36.

29. Walbeehm ET, Afoke A, De Wit T, Holman F, Hovius SER, Brown RA. Mechanical functioning of peripheral nerves: linkage with the "mushrooming" effect. Cell Tissue Res. 2004;316:11521.

30. Ikeda K, Tomita K, Tanaka S. Experimental study of peripheral nerve injury during gradual limb elongation. Hand Surg. 2000;5: 41-7.

31. Xu D, Zhao C, Ma H, Wei J, Li D. Comparison of viscoelasticity between normal human sciatic nerve and amniotic membrane. Neural Regen Res. 2013;8:1269-75.

32. Beel JA, Groswald DE, Luttges MW. Alterations in the mechanical properties of peripheral nerve following crush injury. $\mathrm{J}$ Biomech. 1984;17:185-93.

33. Wong YR, Pang X, Lim ZY, Du H, Tay SC, McGrouther DA. Biomechanical evaluation of peripheral nerves after crush injuries. Heliyon. 2019;5:e1557.

34. Wang ML, Rivlin M, Graham JG, Beredjiklian PK. Peripheral nerve injury, scarring, and recovery. Connect Tissue Res. 2019;60:3-9.

35. Chrząszcz P, Derbisz K, Suszyński K, Miodoński J, Trybulski R, Lewin-Kowalik J, et al. Application of peripheral nerve conduits in clinical practice: a literature review. Neurol Neurochir Pol. 2018;52:427-35.

36. Shin RH, Friedrich PF, Crum BA, Bishop AT, Shin AY. Treatment of a segmental nerve defect in the rat with use of bioabsorbable synthetic nerve conduits: a comparison of commercially available conduits. J Bone Jt Surg - Ser A. 2009;91:2194-204.

37. Navissano M, Malan F, Carnino R, Battiston B. Neurotube ${ }^{\circledR}$ for facial nerve repair. Microsurgery. 2005;25:268-71.

38. Carnicer-Lombarte A, Barone D, Dimov I, et al. Mechanical matching of implant to host minimises foreign body reaction. bioRxiv. 2019:1-53.

39. Engler AJ, Sen S, Sweeney HL, Discher DE. Matrix elasticity directs stem cell lineage specification. Cell. 2006;126:677-89.

40. Quan Q, Meng HY, Chang B, Liu GB, Cheng XQ, Tang H, et al. Aligned fibers enhance nerve guide conduits when bridging peripheral nerve defects focused on early repair stage. Neural Regen Res. 2019;14:903-12.

41. Bettinger CJ. Recent advances in materials and flexible electronics for peripheral nerve interfaces. Bioelectron Med. 2018;4:1-10.

42. Vatankhah-Varnosfaderani M, Daniel WFM, Everhart MH, Pandya AA, Liang H, Matyjaszewski K, et al. Mimicking biological stress-strain behaviour with synthetic elastomers. Nature. 2017;549:497-501.
43. Yan B, Huang J, Han L, Gong L, Li L, Israelachvili JN, et al. Duplicating dynamic strain-stiffening behavior and nanomechanics of biological tissues in a synthetic self-healing flexible network hydrogel. ACS Nano. 2017;11:11074-81.

44. Giannessi E, Stornelli MR, Sergi PN. A unified approach to model peripheral nerves across different animal species. PeerJ. 2017;2017:1-22.

45.• Jessen KR, Mirsky R. The repair Schwann cell and its function in regenerating nerves. J Physiol. 2016;594:3521-31. Provides an overview of the role of the repair Schwann cell in creating a microenvironment supportive of neural regeneration. This is important when developing cell based therapies to support axonal regeneration.

46. Jessen KR, Mirsky R, Lloyd AC. Schwann cells: development and role in nerve repair. Cold Spring Harb Perspect Biol. 2015. https:// doi.org/10.1101/cshperspect.a020487.

47. Deumens R, Bozkurt A, Meek MF, Marcus MAE, Joosten EAJ, Weis J, et al. Repairing injured peripheral nerves: bridging the gap. Prog Neurobiol. 2010. https://doi.org/10.1016/j.pneurobio.2010. 10.002

48. Cooney DS, Wimmers EG, Ibrahim Z, Grahammer J, Christensen $\mathrm{JM}$, Brat GA, et al. Mesenchymal stem cells enhance nerve regeneration in a rat sciatic nerve repair and hindlimb transplant model. Sci Rep. 2016;6:1-12. https://doi.org/10.1038/srep31306.

49. Rodríguez Sánchez DN, de Lima Resende LA, Boff Araujo Pinto G, de Carvalho Bovolato AL, Possebon FS, Deffune E, et al. Canine adipose-derived mesenchymal stromal cells enhance neuroregeneration in a rat model of sciatic nerve crush injury. Cell Transplant. 2019;28:47-54.

50. Wang Y, Zhao Z, Ren Z, Zhao B, Zhang L, Chen J, et al. Recellularized nerve allografts with differentiated mesenchymal stem cells promote peripheral nerve regeneration. Neurosci Lett. 2012;514:96-101.

51. Peng J, Wang Y, Zhang L, Zhao B, Zhao Z, Chen J, et al. Human umbilical cord Wharton's jelly-derived mesenchymal stem cells differentiate into a Schwann-cell phenotype and promote neurite outgrowth in vitro. Brain Res Bull. 2011;84:235-43.

52. Jung N, Park S, Choi Y, et al. Tonsil-derived mesenchymal stem cells differentiate into a Schwann cell phenotype and promote peripheral nerve regeneration. Int J Mol Sci. 2016;17:1867.

53. Takahashi K, Tanabe K, Ohnuki M, Narita M, Ichisaka T, Tomoda $\mathrm{K}$, et al. Induction of pluripotent stem cells from adult human fibroblasts by defined factors. Cell. 2007;131:861-72.

54. Okita K, Matsumura Y, Sato Y, Okada A, Morizane A, Okamoto $\mathrm{S}$, et al. A more efficient method to generate integration-free human iPS cells. Nat Methods. 2011;8:409-12.

55. McLaren A. Ethical and social considerations of stem cell research. Nature. 2001;414:129-31.

56. Normile D. First-of-its-kind clinical trial will use reprogrammed adult stem cells to treat Parkinson's. Science. 2018;(80). https:// doi.org/10.1126/science.aau9466. The findings of this paper will inform the development of cell based therapies to improve peripheral nerve repair.

57. School U of MM (2019) First-ever US clinical trial of engineered iPSC-derived cell therapy for blood cancer. In: Med. Xpress.

58. Normile D. iPS cell therapy reported safe. Science. 2017;355: 1109-10.

59. Kim HS, Lee J, Lee DY, Kim YD, Kim JY, Lim HJ, et al. Schwann cell precursors from human pluripotent stem cells as a potential therapeutic target for myelin repair. Stem Cell Reports. 2017. https://doi.org/10.1016/j.stemcr.2017.04.011.

60. Huang CW, Huang WC, Qiu X, Fernandes Ferreira Da Silva F, Wang A, Patel S, et al. The differentiation stage of transplanted stem cells modulates nerve regeneration. Sci Rep. 2017;7:1-12. https://doi.org/10.1038/s41598-017-17043-4. 
61. Bhatheja K, Field J. Schwann cells: origins and role in axonal maintenance and regeneration. Int J Biochem Cell Biol. 2006. https://doi.org/10.1016/j.biocel.2006.05.007.

62. Clements MP, Byrne E, Camarillo Guerrero LF, et al. The wound microenvironment reprograms Schwann cells to invasive mesenchymal-like cells to drive peripheral nerve regeneration. Neuron. 2017;96:98-114.e7.

63. Rao F, Zhang D, Fang T, et al. Exosomes from human gingivaderived mesenchymal stem cells combined with biodegradable chitin conduits promote rat sciatic nerve regeneration. Stem Cells Int. 2019;2019:1-12.

64. Liu C, Yin G, Sun Y, Lin Y, Xie Z, English AW, et al. Effect of exosomes from adipose-derived stem cells on the apoptosis of Schwann cells in peripheral nerve injury. CNS Neurosci Ther CNS. 2019:13187.

65. Ching RC, Wiberg M, Kingham PJ. Schwann cell-like differentiated adipose stem cells promote neurite outgrowth via secreted exosomes and RNA transfer. Stem Cell Res Ther. 2018;9:266.

66. Eggers R, De Winter F, Hoyng SA, Hoeben RC, Malessy MJA, Tannemaat MR, et al. Timed GDNF gene therapy using an immune-evasive gene switch promotes long distance axon regeneration. Brain. 2019;142:295-311.

67. Huang L, Xia B, Shi X, Gao J, Yang Y, Xu F, Qi F, Liang C, Huang J, Luo Z (2019) Time-restricted release of multiple neurotrophic factors promotes axonal regeneration and functional recovery after peripheral nerve injury. FASEB J fj.201802065RR. This paper demonstrates that the timing of growth factor release represents an important consideration in the development of therapies to created a tissue microenvironment supportive of regeneration.

68. Dun XP, Carr L, Woodley PK, Barry RW, Drake LK, Mindos T, et al. Macrophage-derived Slit3 controls cell migration and axon pathfinding in the peripheral nerve bridge. Cell Rep. 2019;26: 1458-1472.e4.

69. Chen B, Carr L, Dun XP. Dynamic expression of Slit1-3 and Robo1-2 in the mouse peripheral nervous system after injury. Neural Regen Res. 2020;15:948-58.

70. Cattin AL, Burden JJ, Van Emmenis L, et al. Macrophage-induced blood vessels guide Schwann cell-mediated regeneration of peripheral nerves. Cell. 2015. https://doi.org/10.1016/j.cell.2015. 07.021 .

71. Gordan JD, Bertout JA, Hu CJ, Diehl JA, Simon MC. HIF- $2 \alpha$ promotes hypoxic cell proliferation by enhancing c-Myc transcriptional activity. Cancer Cell. 2007;11:335-47.

72. Ma B, Li M, Fuchs S, Bischoff I, Hofmann A, Unger RE, et al. Short-term hypoxia promotes vascularization in co-culture system consisting of primary human osteoblasts and outgrowth endothelial cells. J Biomed Mater Res - Part A. 2020;108:7-18.

73. Sanen K, Martens W, Georgiou M, Ameloot M, Lambrichts I, Phillips J. Engineered neural tissue with Schwann cell differentiated human dental pulp stem cells: potential for peripheral nerve repair? J Tissue Eng Regen Med. 2017;11:3362-72.

74. Krock BL, Skuli N, Simon MC. Hypoxia-induced angiogenesis: good and evil. Genes and Cancer. 2011;2:1117-33.

75. Mazure NM, Pouysségur J. Hypoxia-induced autophagy: cell death or cell survival? Curr Opin Cell Biol. 2010;22:177-80.

76. Nishida Y, Yamada Y, Kanemaru H, Ohazama A, Maeda T, Seo K. Vascularization via activation of VEGF-VEGFR signaling is essential for peripheral nerve regeneration. Biomed Res. 2018;39: 287-94.

77. Raimondo TM, Li H, Kwee BJ, Kinsley S, Budina E, Anderson $\mathrm{EM}$, et al. Combined delivery of VEGF and IGF-1 promotes functional innervation in mice and improves muscle transplantation in rabbits. Biomaterials. 2019;216:119246.
78. Coy RH, Evans OR, Phillips JB, Shipley RJ. An integrated theoretical-experimental approach to accelerate translational tissue engineering. J Tissue Eng Regen Med. 2018;12:e53-9.

79. Georgiou M, Golding JP, Loughlin AJ, Kingham PJ, Phillips JB. Engineered neural tissue with aligned, differentiated adiposederived stem cells promotes peripheral nerve regeneration across a critical sized defect in rat sciatic nerve. Biomaterials. 2015;37: 242-51.

80. Gonzalez-Perez F, Hernandez J, Heimann C, Phillips JB, Udina E, Navarro X. Schwann cells and mesenchymal stem cells in laminin- or fibronectin-aligned matrices and regeneration across a critical size defect of $15 \mathrm{~mm}$ in the rat sciatic nerve. J Neurosurg Spine. 2018;28:109-18.

81. O'Rourke C, Day AGE, Murray-Dunning C, et al. An allogeneic "off the shelf" therapeutic strategy for peripheral nerve tissue engineering using clinical grade human neural stem cells. Sci Rep. 2018;8:2951-62.

82. Georgiou M, Bunting SCJ, Davies HA, Loughlin AJ, Golding JP, Phillips JB. Engineered neural tissue for peripheral nerve repair. Biomaterials. 2013;34:7335-43.

83. Jessen KR, Mirsky R. The success and failure of the Schwann cell response to nerve injury. Front Cell Neurosci. 2019;13:33.

84. Wilcox M, Quick TJ, Phillips JB. The effects of surgical antiseptics and time delays on RNA isolated from human and rodent peripheral nerves. Front Cell Neurosci. 2019;13:189.

85. Bhardwaj P, Bhardwaj N. Motor grading of elbow flexion - is Medical Research Council grading good enough? J Brachial Plex Peripher Nerve Inj. 2009;4:3.

86. MacAvoy MC, Green DP. Critical reappraisal of Medical Research Council muscle testing for elbow flexion. J Hand Surg Am. 2007;32:149-53.

87. Quick TJ, Singh AK, Fox M, Sinisi M, MacQuillan A. A quantitative assessment of the functional recovery of flexion of the elbow after nerve transfer in patients with a brachial plexus injury. Bone Joint J. 2016;98-B:1517-20.

88. Chammas M, Micallef JP, Prefaut C, Allieu Y. Fatigue analysis of human reinnervated muscle after microsurgical nerve repair. Clin Orthop Relat Res. 1997:144-9.

89. Brown H, Johnson K, Gilbert A, Quick TJ. The lived experience of motor recovery of elbow flexion following Oberlin nerve transfer: a qualitative analysis. Hand Ther. 2018;23:130-8.

90. Wilcox M, Brown H, Johnson K, Sinisi M, Quick T. An assessment of fatigability following nerve transfer to reinnervate elbow flexor muscles. Bone Joint J. 2019;101-B:867-71.

91. Allen DG, Lamb GD, Westerblad H. Skeletal muscle fatigue: cellular mechanisms. Physiol Rev. 2008;88:287-332.

92. Smith S, Knight R. Clinical neurophysiology in peripheral nerve injuries BT - surgical disorders of the peripheral nerves. In: Birch R, editor. . London: Springer London; 2011. p. 191-229.

93. Wu P, Chawla A, Spinner RJ, Yu C, Yaszemski MJ, Windebank $\mathrm{AJ}$, et al. Key changes in denervated muscles and their impact on regeneration and reinnervation. Neural Regen Res. 2014;9:1796809.

94. McComas AJ, Fawcett PR, Campbell MJ, Sica RE. Electrophysiological estimation of the number of motor units within a human muscle. J Neurol Neurosurg Psychiatry. 1971;34:121-31.

95. de Carvalho M, Barkhaus PE, Nandedkar SD, Swash M. Motor unit number estimation (MUNE): where are we now? Clin Neurophysiol. 2018;129:1507-16.

96. Gooch CL, Doherty TJ, Chan KM, Bromberg MB, Lewis RA, Stashuk DW, et al. Motor unit number estimation: a technology and literature review. Muscle Nerve. 2014;50:884-93.

97. Gooch CL, Harati Y. Motor unit number estimation, ALS and clinical trials. Amyotroph Lateral Scler Other Motor Neuron Disord. 2000;1:71-82. 
98. Jacobsen AB, Bostock H, Tankisi H. CMAP Scan MUNE (MScan) - A novel motor unit number estimation (MUNE) method. JoVE. 2018:e56805.

99. Bromberg MB. Updating motor unit number estimation (MUNE). Clin Neurophysiol. 2007;118:1-8.

$100 . \bullet$ MLD R, Brown HL, Wilcox M, Phillips JB, Quick TJ. Quantifying regeneration in patients following peripheral nerve injury. J Plast Reconstr Aesthetic Surg. 2019. https://doi.org/10. 1016/j.bjps.2019.10.007. Effective measures of nerve regeneration represent a major obstacle to the development of new therapies to improve peripheral nerve repair. This paper provides an overview of new methods to quantify nerve regeneration in patients.

101. Kamath S, Venkatanarasimha N, Walsh MA, Hughes PM. MRI appearance of muscle denervation. Skelet Radiol. 2008;37:397404.

102. Bendszus M, Koltzenburg M. Visualization of denervated muscle by gadolinium-enhanced MRI. Neurology. 2001;57:1709-11.

103. Bendszus M, Koltzenburg M, Wessig C, Solymosi L. Sequential MR imaging of denervated muscle: experimental study. AJNR Am J Neuroradiol. 2002;23:1427-31.

104. Wessig C, Koltzenburg M, Reiners K, Solymosi L, Bendszus M. Muscle magnetic resonance imaging of denervation and reinnervation: correlation with electrophysiology and histology. Exp Neurol. 2004;185:254-61.

105. Bendszus M, Stoll G. Technology insight: visualizing peripheral nerve injury using MRI. Nat Clin Pract Neurol. 2005;1:45-53.

106. Bendszus M, Wessig C, Reiners K, Bartsch AJ, Solymosi L, Koltzenberg M. MR imaging in the differential diagnosis of neurogenic foot drop. AJNR Am J Neuroradiol. 2003;24:1283-9.

107. Koltzenburg M, Bendszus M. Imaging of peripheral nerve lesions. Curr Opin Neurol. 2004;17:621-6.

108. Simon NG, Kliot M. Diffusion weighted MRI and tractography for evaluating peripheral nerve degeneration and regeneration. Neural Regen Res. 2014;9:2122-4.

109. Aagaard BD, Lazar DA, Lankerovich L, Andrus K, Hayes CE, Maravilla K, et al. High-resolution magnetic resonance imaging is a noninvasive method of observing injury and recovery in the peripheral nervous system. Neurosurgery. 2003;53:194-9.

110. Kullmer K, Sievers KW, Reimers CD, Rompe JD, Muller-Felber $\mathrm{W}$, Nagele $\mathrm{M}$, et al. Changes of sonographic, magnetic resonance tomographic, electromyographic, and histopathologic findings within a 2-month period of examinations after experimental muscle denervation. Arch Orthop Trauma Surg. 1998;117:228-34.

111. Polak JF, Jolesz FA, Adams DF. Magnetic resonance imaging of skeletal muscle. Prolongation of T1 and T2 subsequent to denervation. Investig Radiol. 1988;23:365-9.

112. Simon NG, Talbott J, Chin CT, Kliot M. Peripheral nerve imaging. Handb Clin Neurol. 2016;136:811-26.

113. Kobayashi J, Mackinnon SE, Watanabe O, Ball DJ, Gu XM, Hunter DA, et al. The effect of duration of muscle denervation on functional recovery in the rat model. Muscle Nerve. 1997;20: 858-66.

114. Bain JR, Veltri KL, Chamberlain D, Fahnestock M. Improved functional recovery of denervated skeletal muscle after temporary sensory nerve innervation. Neuroscience. 2001;103:503-10.

115. Brown DL, Bennett TM, Dowsing BJ, Hayes A, Abate M, Morrison WA. Immediate and delayed nerve repair: improved muscle mass and function with leukemia inhibitory factor. $\mathrm{J}$ Hand Surg Am. 2002;27:1048-55.

116. Viddeleer AR, Sijens PE, van Ooyen PMA, Kuypers PDL, Hovius SER, Oudkerk M. Sequential MR imaging of denervated and reinnervated skeletal muscle as correlated to functional outcome. Radiology. 2012;264:522-30.

117. Viddeleer AR, Sijens PE, van Ooijen PMA, Kuypers PDL, Hovius SER, De Deyn PP, et al. Quantitative STIR of muscle for monitoring nerve regeneration. J Magn Reson Imaging. 2016;44:40110.

118. Suk JI, Walker FO, Cartwright MS. Ultrasonography of peripheral nerves. Curr Neurol Neurosci Rep. 2013;13:328.

Publisher's Note Springer Nature remains neutral with regard to jurisdictional claims in published maps and institutional affiliations. 